\title{
Consenso | Protocolo Brasileiro para Infecções Sexualmente Transmissíveis 2020: síflis congênita e criança exposta à sífilis
}

doi: 10.1590/\$1679-4974202100005.esp1

\author{
Brazilian Protocol for Sexually Transmitted Infections 2020: congenital syphilis \\ and child exposed to syphilis
}

\author{
Protocolo Brasileño para Infecciones de Transmisión Sexual 2020: sífilis congénita \\ y niño expuesto a la sífilis
}

\author{
Carmen Silvia Bruniera Domingues ${ }^{1}$ - (1) orcid.org/0000-0003-2784-9592 \\ Geraldo Duarte ${ }^{2}$ - (1) orcid.org/0000-0002-1689-6142 \\ Mauro Romero Leal Passos ${ }^{3}$ - (1) orcid.org/0000-0002-6183-7985 \\ Denise Cardoso das Neves Sztajnbok ${ }^{4}$ - (1) orcid.org/0000-0003-0256-7118 \\ Maria Luiza Bezerra Menezes ${ }^{5}$ - (1) orcid.org/0000-0001-7001-2005 \\ 'Secretaria de Estado da Saúde de São Paulo, Centro de Referência e Treinamento de Doenças Sexualmente Transmissíveis e Aids, \\ São Paulo, SP, Brasil \\ 2Universidade de São Paulo, Faculdade de Medicina de Ribeirão Preto, Ribeirão Preto, SP, Brasil \\ ${ }^{3}$ Universidade Federal Fluminense, Departamento de Microbiologia e Parasitologia, Niterói, RJ, Brasil \\ ${ }^{4}$ Universidade do Estado do Rio de Janeiro, Faculdade de Ciências Médicas, Rio de Janeiro, RJ, Brasil \\ ${ }^{5}$ Universidade de Pernambuco, Departamento Materno-Infantil, Recife, PE, Brasil
}

\section{Resumo}

Os temas sífilis congênita e criança exposta à sífilis compõem o Protocolo Clínico e Diretrizes Terapêuticas para Atenção Integral às Pessoas com Infecções Sexualmente Transmissíveis, publicado pelo Ministério da Saúde do Brasil em 2020. Tal documento foi elaborado com base em evidências científicas e validado em discussões com especialistas. Este artigo apresenta orientações para 0 manejo clínico da sífilis em gestantes e da sífilis congênita, enfatizando a prevenção da transmissão vertical do Treponema pallidum. Nele estão contemplados aspectos epidemiológicos e clínicos desses agravos, bem como recomendações aos gestores no manejo programático e operacional da sífilis. Também se incluem orientações para os profissionais de saúde na triagem, diagnóstico e tratamento das pessoas com infecções sexualmente transmissíveis e suas parcerias sexuais, além de estratégias para ações de vigilância, prevenção e controle da doença.

Palavras-chave: Sífilis; Sífilis Congênita; Cuidado Pré-Natal; Diagnóstico; Terapêutica; Monitoramento.

Endereço para correspondência:

Maria Luiza Bezerra Menezes - Universidade de Pernambuco, Departamento Materno-Infantil, Rua Visconde de Mamanguape s/n, Encruzilhada, Recife, PE, Brasil. CEP: 52030-010

E-mail: luiza.menezes.24.09@gmail.com 


\section{Apresentação}

0 presente artigo aborda os temas sífilis congênita e criança exposta à sífilis, que compõem o Protocolo Clínico e Diretrizes Terapêuticas (PCDT) para Atenção Integral às Pessoas com Infecções Sexualmente Transmissíveis (IST), publicado pela Secretaria de Vigilância em Saúde, do Ministério da Saúde do Brasil. Para a elaboração do PCDT, foram realizadas seleção e análise das evidências disponíveis na literatura, e discussão em um painel de especialistas. 0 PCDT foi aprovado pela Comissão Nacional de Incorporação de Tecnologias no Sistema Único de Saúde (Conitec) ${ }^{1}$ e atualizado pelo grupo de especialistas em IST em 2020.

\section{A maior parte dos casos de síflis congênita é decorrente de falhas na testagem durante o pré-natal, ou de tratamento inadequado ou ausente da síflis materna.}

\section{Aspectos epidemiológicos}

Em 2016, foram estimados 661.000 casos de sífilis congênita no mundo. ${ }^{2}$ No Brasil, entre os anos $2014 \mathrm{e}$ 2018, houve crescimento no número de casos de sífilis adquirida na população adulta, sífilis em gestantes e sífilis congênita. ${ }^{3}$ Essa elevação pode ser atribuída ao incremento na testagem, decorrente da disseminação dos testes rápidos, mas também à diminuição no uso de preservativos, à redução na administração da penicilina nos serviços de atenção primária à saúde e ao desabastecimento mundial desse medicamento. ${ }^{4}$ Entre 2010 e 2019 (dados de até 30/06/2019), o país registrou 650.258 casos de sífilis adquirida, 297.003 casos de sífilis em gestantes e 162.173 casos de sífilis congênita. No mesmo período, foram notificadas 11.480 mortes fetais precoces e tardias, atribuídas à sífilis congênita. ${ }^{3}$

A sífilis congênita é agravo evitável, desde que a sífilis gestacional seja diagnosticada e tratada oportunamente. Entretanto, apesar dos esforços, ainda permanece como grave problema de saúde pública e evidencia lacunas especialmente na assistência pré-natal. A maior parte dos casos de sífilis congênita é decorrente de falhas na testagem durante o pré-natal, ou de tratamento inadequado ou ausente da sífilis materna. ${ }^{5-7}$ É resultado da disseminação hematogênica do Treponema pallidum da gestante infectada não tratada ou inadequadamente tratada para 0 seu concepto, geralmente por via transplacentária, independentemente da idade gestacional. ${ }^{4}$ Eventualmente, essa transmissão pode ocorrer durante 0 nascimento, por contato direto com lesões de sífilis no canal de parto. ${ }^{8-10}$

A passagem transplacentária do treponema durante a gestação pode ocorrer em qualquer estágio clínico da sífilis materna. No entanto, a transmissão vertical é mais frequente na sífilis recente (lesões primárias, lesões secundárias e sífilis latente recente até um ano) e se reduz com a evolução da doença para as fases tardias (latente tardia após um ano e tardia, no terciarismo da sífilis).$^{11}$ A redução na probabilidade de transmissão está diretamente relacionada à diminuição de treponemas circulantes, passando de $70 \%$ a $100 \%$ na sífilis com lesões primárias ou secundárias para $30 \%$ na latência recente ou tardia da sífilis. ${ }^{6,12}$ Além de se caracterizar pela maior transmissibilidade, a fase recente da sífilis materna pode afetar mais gravemente 0 feto. ${ }^{13} \mathrm{~A}$ carga de treponema circulante diminui, mas não desaparece se não houver tratamento adequado. Além dos estágios clínicos da sífilis, a ocorrência de transmissão vertical também é influenciada pelo tempo que 0 feto foi exposto. ${ }^{4}$

Entre os desfechos adversos resultantes da sífilis materna recente não tratada, $40 \%$ resultarão em perdas gestacionais precoces, $11 \%$ em morte fetal a termo e $12 \%$ a $13 \%$ em partos pré-termo ou baixo peso ao nascer. ${ }^{2,14}$ Pelo menos $20 \%$ dos recém-nascidos apresentarão sinais sugestivos de sífilis congênita., ${ }^{2,12,15}$

\section{Aspectos clínicos}

A sífilis congênita é uma doença com amplo espectro clínico e pode se manifestar desde as formas assintomáticas ou oligossintomáticas até às formas graves, com quadros sépticos, óbitos fetais e neonatais. No nascimento, cerca de $60 \%$ a $90 \%$ dos recém-nascidos com sífilis congênita são assintomáticos ${ }^{16,17} \mathrm{e}$, por isso, a triagem sorológica da gestante na maternidade é importante. As manifestações clínicas das crianças com sífilis congênita podem se apresentar a qualquer momento antes dos 2 anos de idade, geralmente no período neonatal. Cerca de dois terços das crianças desenvolvem sintomas em três a oito semanas, e raramente surgem manifestações clínicas após três a quatro meses. ${ }^{18}$ 
Didaticamente, divide-se a sífilis congênita em precoce, aquela que surge até o segundo ano de vida, e tardia, quando os sinais e sintomas são observados a partir do segundo ano de vida. Nos casos de sífilis congênita precoce, a presença de sinais e sintomas ao nascimento depende do momento da infecção intrauterina e do tratamento durante a gestação. ${ }^{19}$ São manifestações frequentes na sífilis congênita precoce: hepatomegalia, esplenomegalia, icterícia, rinite serossanguinolenta, erupção cutânea maculopapular, pênfigo sifilítico (principalmente palmo-plantar), linfadenopatia generalizada, anormalidades esqueléticas (periostite, osteocondrite), trombocitopenia e anemia. A prematuridade e 0 baixo peso ao nascer são complicações perinatais frequentes. ${ }^{17,20}$

As manifestações clínicas da sífilis congênita tardia estão relacionadas à inflamação cicatricial ou persistente da infecção precoce e se caracterizam pela presença de formação das gomas sifilíticas em diversos tecidos. Essas manifestações surgem em aproximadamente $40 \%$ das crianças infectadas e não tratadas nos primeiros meses de vida. Algumas manifestações podem ser prevenidas por meio do tratamento materno durante a gestação ou do tratamento da criança nos primeiros três meses de vida. ${ }^{21}$ Outras, porém, como ceratite intersticial, articulações de Clutton e surdez neurossensorial podem ocorrer e progredir, a despeito de terapêutica apropriada. ${ }^{22}$ Em casos de sífilis congênita tardia, deve ser afastada a possibilidade de sífilis adquirida, decorrente de agressão ou abuso sexual da criança.

As manifestações da sífilis congênita tardia mais citadas são: fronte olímpica, nariz em sela, palato em ogiva, ceratite intersticial, coriorretinite, perda auditiva sensorial, dentes de Hutchinson, molares em amora, atraso no desenvolvimento, comprometimento intelectual e tíbia em sabre. ${ }^{19}$

As alterações clínicas da sífilis congênita, após a liberação do T. pallidum diretamente na circulação fetal, são variáveis e decorrem da resposta inflamatória ocasionada pela ampla disseminação das espiroquetas por quase todos os órgãos e sistemas. Consequentemente, são necessários exames complementares para investigar e identificar essas alterações, ${ }^{19}$ como hemograma completo, transaminases, radiografia de tórax, radiografia de ossos longos, exame de líquor e neuroimagem, quando necessário. ${ }^{4}$
A infecção no sistema nervoso central ou neurossífilis pode ser sintomática ou assintomática e ocorre em cerca de $60 \%$ das crianças com sífilis congênita. São consideradas alterações no líquor: reatividade no venereal disease research laboratory (VDRL), pleocitose e aumento na proteinorraquia. ${ }^{21}$ No período neonatal, consideram-se neurossífilis as seguintes situações: VDRL reagente no líquor ou leucócitos superiores a 25 células $/ \mathrm{mm}^{3}$ ou proteína superior a $150 \mathrm{mg} /$ dL, e, no período pós-neonatal, VDRL reagente no líquor ou leucócitos superiores a 5 células $/ \mathrm{mm}^{3}$ ou proteína superior a $40 \mathrm{mg} / \mathrm{dL}$. ${ }^{23}$ Para a adequada avaliação desses valores, o líquor deve estar livre de qualquer contaminação por sangue, que possa ocorrer em casos de acidente de punção.

\section{Diagnóstico}

0 diagnóstico etiológico de sífilis adquirida exige correlação entre dados clínicos, resultados de testes laboratoriais, histórico de infecções passadas devidamente registradas em prontuário e investigação de exposição recente. Apenas o conjunto de todas essas informações permitirá a correta avaliação diagnóstica de cada caso e o tratamento adequado.

Os testes utilizados para o diagnóstico de sífilis são divididos em duas categorias: diretos e imunológicos. Os exames diretos incluem a pesquisa de T. pallidum em amostras coletadas de lesões, utilizando microscopia de campo escuro, impregnação pela prata, imunofluorescência ou técnicas de biologia molecular por reação de cadeia da polimerase. 0 s testes imunológicos, testes treponêmicos (TT) e testes não treponêmicos (TNT), são os mais utilizados e caracterizam-se pela pesquisa de anticorpos em amostras de sangue total, soro, plasma ou líquor. ${ }^{4}$

0s TT detectam anticorpos específicos produzidos contra os antígenos do T. pallidum e os TNT detectam anticorpos não específicos para os antígenos do T. pallidum (anticardiolipina). ${ }^{4}$ Ressalta-se que os testes rápidos são TT. Os testes imunológicos utilizados para o diagnóstico de sífilis estão apresentados na Figura 1.

As gestantes devem ser testadas para sífilis, no mínimo, na primeira consulta de pré-natal, no início do terceiro trimestre, e no momento da internação para 0 parto. Também devem ser testadas as mulheres que apresentarem perdas fetais precoces e tardias ou aquelas submetidas a situações de exposição de risco 


\begin{tabular}{|c|c|c|}
\hline $\begin{array}{l}\text { Testes } \\
\text { imunológicos }\end{array}$ & Tipos & Observações \\
\hline \multirow{4}{*}{ Não treponêmicos } & Venereal disease research laboratory (VDRL) & \multirow{4}{*}{$\begin{array}{l}\text { Quantificáveis (ex.: 1:2, 1:4, 1:8). } \\
\text { Importantes para o diagnóstico e monitoramento da resposta } \\
\text { ao tratamento. }\end{array}$} \\
\hline & Rapid plasma reagin (RPR) & \\
\hline & Toluidine red unheated serum test (TRUST) & \\
\hline & Unheated-serum reagin (USR) & \\
\hline \multirow{7}{*}{ Treponêmicos } & Testes rápidos & \multirow{7}{*}{$\begin{array}{l}\text { São os primeiros a se tornarem reagentes. } \\
\text { Na maioria das vezes, permanecem reagentes por toda a vida } \\
\text { mesmo após o tratamento. } \\
\text { São importantes para o diagnóstico, mas não estão indicados } \\
\text { para monitoramento da resposta ao tratamento. }\end{array}$} \\
\hline & $\begin{array}{l}\text { Teste de imunofluorescência indireta - Fluorescent treponemal } \\
\text { antibody-absorption (FTA-Abs) }\end{array}$ & \\
\hline & $\begin{array}{l}\text { Ensaios imunoenzimáticos - Enzyme-linked immunossorbent } \\
\text { assay (ELISA) }\end{array}$ & \\
\hline & $\begin{array}{l}\text { Ensaio imunológico com revelação quimioluminescente e suas } \\
\text { derivações - Electrochemiluminescence (EQL) e Chemiluminescent } \\
\text { magnetic immunoassay (CMIA) }\end{array}$ & \\
\hline & $\begin{array}{l}\text { Teste de hemaglutinação - T. pallidum haemagglutination test } \\
\text { (TPHA) }\end{array}$ & \\
\hline & $\begin{array}{l}\text { Teste de aglutinação de partículas - T. pallidum particle } \\
\text { agglutination assay (TPPA) }\end{array}$ & \\
\hline & $\begin{array}{l}\text { Ensaios de micro-hemaglutinação - Micro-haemagglutination } \\
\text { assay (MHA-TP) }\end{array}$ & \\
\hline
\end{tabular}

Fonte: adaptado do Protocolo Clínico e Diretrizes Terapêuticas para Atenção Integral às Pessoas com Infecções Sexualmente Transmissíveis, 2020. ${ }^{4}$

Figura 1 - Testes imunológicos utilizados para o diagnóstico de sífilis

ou violência sexual. ${ }^{24}$ Considerando a sensibilidade dos fluxos diagnósticos, recomenda-se, preferencialmente, iniciar a investigação com TT, se possível, testes rápidos. A combinação de testes sequenciais aumenta 0 valor preditivo positivo do resultado reagente no teste inicial. ${ }^{4}$ Gestantes com testes rápidos reagentes para sífilis deverão ser consideradas como portadoras de sífilis até prova em contrário e, na ausência de tratamento adequado e documentado, deverão ser tratadas na ocasião da consulta pré-natal, no parto ou em situação de abortamento. Ainda nesse momento, deve ser solicitado e colhido teste confirmatório, no caso um TNT (linha de base) para monitoramento da resposta ao tratamento. ${ }^{4} 0$ retardo do tratamento em função da espera do resultado de teste complementar faz com que o profissional perca tempo e oportunidade de evitar um caso de sífilis congênita. Ressalta-se a importância de boa documentação da história clínica e de exames laboratoriais e tratamentos realizados nos prontuários dessas mulheres, para a adequada condução dos casos de sífilis.

A avaliação inicial para criança exposta à sífilis deve ser realizada prioritariamente na maternidade ou casa de parto, considerando o histórico materno de sífilis quanto ao tratamento e seguimento na gestação, sinais e sintomas clínicos da criança (frequentemente ausentes ou inespecíficos) e o TNT de sangue periférico da criança, comparado simultaneamente ao TNT materno no momento do parto. 0 sangue de cordão umbilical não deve ser utilizado, pois estas amostras de sangue fetal podem apresentar contaminações com o sangue materno e levar a resultados falso-reagentes. ${ }^{4}$

Não existe avaliação complementar que determine com precisão o diagnóstico da infecção na criança. Assim, faz-se necessária uma combinação de avaliação clínica, epidemiológica e laboratorial. ${ }^{25}$ Nessa perspectiva, é importante distinguir adequadamente crianças expostas (mas não infectadas) de crianças com sífilis congênita, para evitar condutas desnecessárias, como exames invasivos e internações prolongadas. ${ }^{4}$

Para exclusão da infecção congênita em criança exposta ao treponema, a mãe deve preencher todos os critérios de tratamento adequado, com confirmação em prontuário ou caderneta da gestante, e o exame físico do recém-nascido deve ser normal. 0 achado de qualquer sinal ou sintoma deve levar à investigação complementar para confirmação do diagnóstico. 
Além do exame físico, o TNT deve ser realizado ao nascimento em toda criança exposta à sífilis. ${ }^{4}$

A testagem simultânea da mãe e do recém-nascido, no pós-parto imediato, com o mesmo tipo de TNT, contribui para a determinação do significado dos achados sorológicos da criança. Um título maior que 0 materno em pelo menos duas diluições (por exemplo, TNT da mãe de 1:4 e TNT do recém-nascido superior a 1:16) é indicativo de infecção congênita. No entanto, a ausência desse achado não exclui a possibilidade do diagnóstico de sífilis congênita. Alguns estudos de pares de soro de mães com sífilis e recém-nascidos demonstraram que menos de $30 \%$ das crianças com sífilis congênita têm resultado de títulos de TNT quatro vezes maior que os maternos. ${ }^{26,27}$ Portanto, é fundamental a realização de exame físico minucioso e seguimento de todas as crianças.

Existem TT capazes de detectar anticorpos do tipo IgM contra o T. pallidum no sangue do recém-nascido, anticorpos estes que não atravessam a barreira placentária e, portanto, quando presentes na amostra da criança, indicam resposta do sistema imune frente à sífilis, e não transferência de anticorpos maternos. Porém, a sensibilidade dos testes baseados em anticorpos IgM é baixa, e um resultado negativo não exclui o diagnóstico de sífilis no recém-nascido. Por isso, não se recomenda a utilização de testes que detectam IgM, como 0 teste de absorção do anticorpo treponêmico fluorescente IgM e os imunoensaios IgM para o diagnóstico da sífilis congênita. ${ }^{4,11,28}$

Diante de qualquer uma das seguintes situações, a criança será considerada caso de sífilis congênita, devendo ser notificada, investigada, imediatamente tratada e acompanhada quanto a aspectos clínicos e laboratoriais: a) mãe com sífilis inadequadamente tratada ou não tratada, independentemente dos resultados da avaliação clínica ou de exames complementares do recém-nascido; b) manifestações clínicas presentes ou alteração liquórica ou radiológica e TNT reagente, independentemente do histórico de tratamento materno e titulação de TNT; c) TNT do recém-nascido maior que o materno em pelo menos duas diluições, independentemente do histórico de tratamento da mãe; e d) persistência de TNT reagente após os 6 meses de idade ou TT reagente após os 18 meses de idade, sem tratamento prévio. Ressalta-se que todas as crianças com sífilis congênita devem ser submetidas à investigação completa, incluindo punção lombar para análise do líquor e radiografia de ossos longos. ${ }^{4}$

Como as manifestações de sífilis congênita são inespecíficas, faz-se necessário o diagnóstico diferencial com outras infecções congênitas, como toxoplasmose, rubéola, citomegalovírus, herpes vírus simplex e vírus Zika, assim como sepse neonatal, hepatite neonatal e hidropisia fetal, principalmente quando o TNT do recém-nascido for não reagente. ${ }^{4}$

\section{Tratamento}

\section{Sifilis na gestação}

A benzilpenicilina benzatina é 0 único medicamento que efetivamente trata a gestante com sífilis e 0 feto, visto que atravessa a barreira transplacentária (Figura 2). A administração da penicilina pode ser realizada em serviços de saúde privados ou públicos, inclusive nas unidades de atenção primária à saúde, ${ }^{29}$ por médicos, enfermeiros ${ }^{30}$ ou farmacêuticos. A reação anafilática à benzilpenicilina benzatina é um evento raro, que pode ocorrer em cerca de $0,002 \%$ dos ca$\operatorname{sos}^{31,32}$ É importante que o intervalo de sete dias entre as doses seja mantido e monitorado, para evitar perdas durante o tratamento. As unidades de saúde devem realizar busca ativa de gestantes faltosas para completar o esquema terapêutico.

0 tratamento realizado com medicamento diferente da benzilpenicilina benzatina durante a gestação é considerado não adequado para evitar a transmissão vertical. Ademais, o tratamento materno somente será considerado adequado se tiver sido iniciado até 30 dias do parto e se o ciclo completo para o estágio clínico de sífilis tiver sido administrado. Gestantes que não se enquadrem nesses critérios serão definidas como inadequadamente tratadas. Por sua vez, o recém-nascido será classificado como caso de sífilis congênita e submetido à avaliação clínica, laboratorial e terapêutica e à notificação epidemiológica ${ }^{4}$ (Figura 2). Importante destacar que, no final de 2017, o tratamento do parceiro sexual foi retirado do critério que define 0 tratamento materno adequado. ${ }^{33}$

Deve-se considerar a sífilis na gestação como uma emergência fetal, devido à elevada proporção de mortes fetais precoces ou tardias relacionadas à falta de tratamento. 0 tratamento deve ser iniciado de imediato, mesmo em gestante assintomática, após um teste reagente para sífilis (TT ou TNT). No entanto, instituir 


\begin{tabular}{|l|l|l|}
\hline Estadiamento & Esquema terapêutico & Seguimento (teste não treponêmico) \\
\hline $\begin{array}{l}\text { Sífilis recente: lesões primárias, lesões } \\
\text { secundárias e latente recente - com até um ano } \\
\text { de evolução. }\end{array}$ & $\begin{array}{l}\text { Benzilpenicilina benzatina 2,4 milhões UI, } \\
\text { intramuscular, dose única (1,2 milhão Ul em cada } \\
\text { glúteo) }\end{array}$ & Teste não treponêmico mensal \\
\hline \multirow{2}{*}{$\begin{array}{l}\text { Sífilis tardia: sífilis latente tardia - com mais } \\
\text { de um ano de evolução ou latente com duração } \\
\text { ignorada e sífilis tardia, com lesões terciárias. }\end{array}$} & $\begin{array}{l}\text { Benzilpenicilina benzatina 2,4 milhões UI, } \\
\text { intramuscular, 1x/semana (1,2 milhão Ul em } \\
\text { cada glúte0) por 3 semanas }\end{array}$ & \multirow{2}{*}{ Teste não treponêmico mensal } \\
\cline { 2 - 2 } Neurossífilis & $\begin{array}{l}\text { Dose total: 7,2 milhões UI, intramuscular } \\
\text { Benzilpenicilina potássica/cristalina, 18-24 } \\
\text { milhões UI, 1x/dia, intravenosa, administrada em } \\
\text { doses de 3-4 milhões Ul, a cada 4 horas ou por } \\
\text { infusão contínua, por 14 dias }\end{array}$ & $\begin{array}{l}\text { Exame de líquor de 6 em 6 meses até } \\
\text { normalização }\end{array}$ \\
\hline
\end{tabular}

Fonte: adaptado do Protocolo Clínico e Diretrizes Terapêuticas para Atenção Integral às Pessoas com Infecções Sexualmente Transmissíveis, 2020. ${ }^{4}$

Nota: a) 0 intervalo entre as doses deve ser de sete dias para completar 0 tratamento.

Figura 2 - Tratamento e monitoramento da sífilis na gestação

o tratamento com apenas um teste reagente não exclui a necessidade de realização do segundo teste, para melhor análise diagnóstica, monitoramento laboratorial (controle de cura) e tratamento das parcerias sexuais. ${ }^{4}$

A reação de Jarisch-Herxheimer é um evento que pode ocorrer durante as 24 horas após a primeira dose de penicilina, em especial nas fases primária ou secundária da sífilis. Caracteriza-se por exacerbação das lesões cutâneas, mal-estar geral, febre, cefaleia e artralgia, que regridem espontaneamente após 12 a 24 horas. Principalmente em gestantes tratadas na segunda metade da gravidez, essa reação pode desencadear trabalho de parto pré-termo. ${ }^{11,24}$ A regressão dos sinais e sintomas de sífilis após o tratamento é indicativa de resposta à terapia. No entanto, o acompanhamento sorológico com TNT pós-tratamento deve ser mensal até o final da gravidez, para avaliar a resposta imunológica. Depois do parto, o seguimento deve ser trimestral até $012^{\circ}$ mês após o diagnóstico da sífilis. ${ }^{4,34}$ Sugere-se que o acompanhamento seja feito com o mesmo TNT do diagnóstico (Figura 1), para evitar que ocorram titulações divergentes entre os diferentes tipos - VDRL ou teste da reagina plasmática rápida. ${ }^{4}$

Tradicionalmente, considera-se sucesso de tratamento a diminuição da titulação do TNT em duas diluições (por exemplo, 1:64 para 1:16) até três meses, após a última dose de penicilina, e quatro diluições (por exemplo, 1:64 para 1:4) até seis meses, com evolução até a sororreversão (TNT não reagente). ${ }^{35}$ Em pacientes portadores do HIV, pode ser considerada uma resposta imunológica adequada, além de TNT não reagente, a queda na titulação em duas diluições em até seis meses para sífilis recente ou em até 12 meses para sífilis tardia. ${ }^{11}$

Após tratamento adequado, a persistência de títulos baixos e estáveis de TNT, com queda prévia da titulação em pelo menos duas diluições, descartando-se nova exposição de risco durante o período analisado, é denominada "cicatriz sorológica" e não caracteriza falha terapêutica. ${ }^{4,11}$ No entanto, TNT com títulos crescentes ou persistentemente altos podem indicar reinfecção, falha terapêutica ou neurossífilis, e novo tratamento deve ser considerado. ${ }^{11}$ Nessa situação, é necessário avaliar o procedimento de execução do exame, uma vez que este é técnico-dependente, e deve ser realizada sorologia para o HIV.

Destaca-se que o tempo gestacional pode não ser suficiente para a queda de dois ou mais títulos de TNT pós-tratamento. Gestantes com títulos baixos (por exemplo, 1:2 ou 1:4) podem não apresentar queda de mais de dois títulos ou resultado não reagente no TNT, mesmo após o parto. Portanto, o mais importante nessa situação é afastar a possibilidade de reinfecção e manter o monitoramento com TNT.

São critérios de retratamento, independentes entre si: a) ausência de redução da titulação em duas diluições no intervalo de seis meses (sífilis recente) ou 12 meses (sífilis tardia), após tratamento adequado; b) aumento da titulação em duas diluições ou mais em TNT; e c) persistência ou recorrência de sinais e sintomas clínicos. ${ }^{4}$ 
0 esquema de retratamento irá depender da fase da doença em que se encontra a gestante. A investigação de neurossífilis por meio de punção lombar (liquórica) está indicada também para gestantes em falha terapêutica, quando não houver exposição sexual no período que justifique reinfecção. Para pessoas vivendo com HIV, a investigação está recomendada em todos os casos de retratamento, independentemente de nova exposição. ${ }^{4}$

A avaliação e 0 tratamento das parcerias sexuais da gestante são cruciais para interromper a cadeia de transmissão da infecção. Um terço das parcerias sexuais de pessoas com sífilis recente desenvolverão sífilis dentro de 30 dias da exposição. ${ }^{4}$ Portanto, além da avaliação clínica e do seguimento laboratorial, se houver exposição à pessoa com sífilis no período de até 90 dias, recomenda-se tratamento presuntivo dessas parcerias, independentemente do estágio clínico ou presença de sinais e sintomas, com dose única de benzilpenicilina benzatina (2,4 milhões UI, intramuscular) e testagem laboratorial. No caso de teste reagente (TT ou TNT), recomenda-se tratamento conforme 0 estágio clínico. ${ }^{4}$

\section{Sífilis congênita e criança exposta à sífilis}

0 tratamento da sífilis congênita no período neonatal é realizado com benzilpenicilina (potássica/ cristalina, procaína ou benzatina), a depender do tratamento materno durante a gestação ou da titulação de TNT do recém-nascido comparado ao materno e dos exames clínicos e laboratoriais da criança. Os casos diagnosticados com sífilis congênita após 1 mês de idade (período pós-neonatal) e aqueles com sífilis adquirida deverão ser tratados com benzilpenicilina potássica/cristalina (Figuras 3 e 4). 0 esquema completo de dez dias com benzilpenicilina potássica/ cristalina ou procaína deve ser administrado mesmo nas situações em que a criança tenha recebido ampicilina por outras causas.

Compete à maternidade ou casa de parto, no momento da alta, referenciar todas as crianças expostas à sífilis e com sífilis congênita, tratadas ou em tratamento, às unidades de saúde, preferencialmente com consulta pré-agendada. 0 seguimento pode ser realizado durante consultas de puericultura na atenção primária ${ }^{36}$ com vigilância e monitoramento cuidadoso de sinais e sintomas sugestivos de sífilis congênita, além dos testes de sífilis e exames complementares (Figura 5). Ressalta-se que o seguimento ambulatorial deve ser garantido a todas as crianças expostas à sífilis ou com sífilis congênita até 18 meses de idade. Importante destacar que nenhuma mãe ou recém-nascido deve deixar a maternidade sem o conhecimento do resultado do teste para sífilis, realizado na admissão para o parto. ${ }^{11}$

\begin{tabular}{|c|c|c|}
\hline Esquema terapêutico & Quem pode receber 0 esquema & Seguimento \\
\hline \multicolumn{3}{|l|}{ Tratamento no período neonatal } \\
\hline $\begin{array}{l}\text { Benzilpenicilina potássica (cristalina) } 50.000 \mathrm{UI} / \mathrm{kg}, \\
\text { intravenosa, de } 12 / 12 \mathrm{~h} \text { na primeira semana de vida e } \\
\text { de } 8 / 8 \mathrm{~h} \text { após a primeira semana de vida, por } 10 \text { dias }\end{array}$ & Criança com ou sem neurossífilis & $\begin{array}{l}\text { Referenciar para seguimento clínico e } \\
\text { laboratorial na puericultura. }\end{array}$ \\
\hline \multirow{2}{*}{$\begin{array}{l}\text { Benzilpenicilina procaína } 50.000 \mathrm{Ul} / \mathrm{kg} \text {, intramuscular, } \\
\text { uma vez ao dia, por } 10 \text { dias }\end{array}$} & Criança sem neurossífilis & \multirow{2}{*}{$\begin{array}{l}\text { Referenciar para seguimento clínico e } \\
\text { laboratorial na puericultura. }\end{array}$} \\
\hline & $\begin{array}{l}\text { É necessário reiniciar o tratamento se houver } \\
\text { atraso de mais de } 24 \text { horas na dose }\end{array}$ & \\
\hline $\begin{array}{l}\text { Benzilpenicilina benzatina } 50.000 \mathrm{Ul} / \mathrm{kg} \text {, } \\
\text { intramuscular, dose única }\end{array}$ & $\begin{array}{l}\text { Crianças nascidas de mães não tratadas ou } \\
\text { tratadas de forma não adequada, com exame } \\
\text { físico normal, exames complementares } \\
\text { normais e teste não treponêmico não } \\
\text { reagente ao nascimento }\end{array}$ & $\begin{array}{l}\text { Referenciar para seguimento clínico e } \\
\text { laboratorial na puericultura. Seguimento } \\
\text { obrigatório. }\end{array}$ \\
\hline \multicolumn{3}{|c|}{ Tratamento no período pós-neonatal e na criança com sífilis adquirida } \\
\hline $\begin{array}{l}\text { Benzilpenicilina potássica (cristalina) } 50.000 \mathrm{Ul} / \mathrm{kg} \text {, } \\
\text { intravenosa, de 4/4h a } 6 / 6 \mathrm{~h} \text {, por } 10 \text { dias }\end{array}$ & $\begin{array}{l}\text { Crianças diagnosticadas com sífilis congênita } \\
\text { após um mês de idade e aquelas com sífilis } \\
\text { adquirida }\end{array}$ & $\begin{array}{l}\text { Referenciar para seguimento clínico e } \\
\text { laboratorial na atenção primária à saúde. }\end{array}$ \\
\hline
\end{tabular}

Fonte: adaptado do Protocolo Clínico e Diretrizes Terapêuticas para Atenção Integral às Pessoas com Infecções Sexualmente Transmissíveis, 2020. ${ }^{4}$

Figura 3 - Esquema terapêutico para a sífilis congênita no período neonatal, pós-neonatal e para crianças com sífilis adquirida 


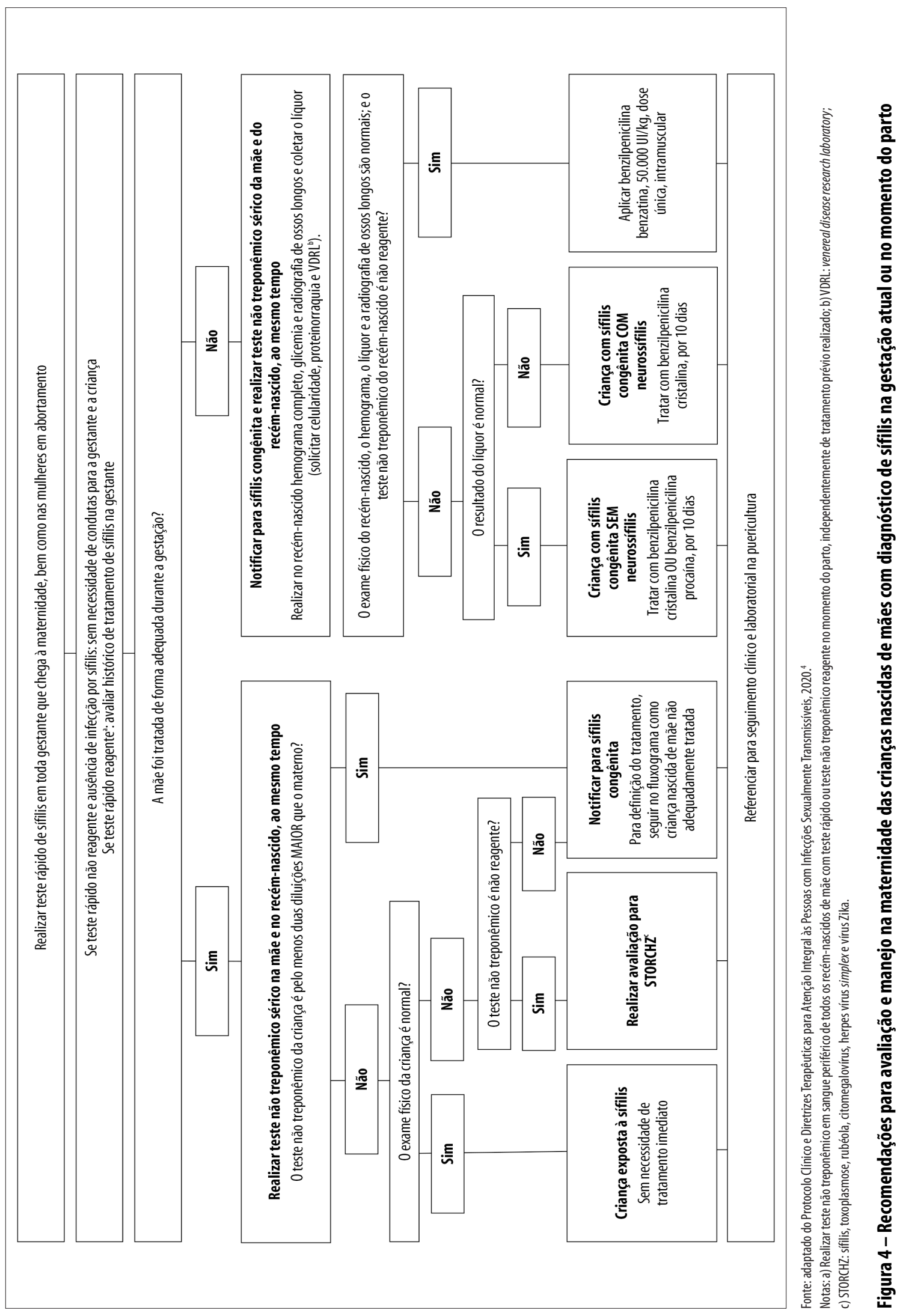




\section{Vigilância, prevenção e controle}

0 Brasil possui cobertura elevada de pré-natal, embora não uniforme. Segundo o Sistema de Informações sobre Nascidos Vivos, a cobertura de sete ou mais consultas pré-natais entre recém-nascidos vivos aumentou de 65\%,em 2014,para 71\%, em 2018. ${ }^{37}$ Porém, a quantidade de consultas não substitui a qualidade desses atendimentos, pois a sífilis congênita continua sendo consequência da sífilis materna não diagnosticada ou não tratada de forma adequada e oportuna. Ações de prevenção à sífilis congênita relacionam-se ao cuidado da gestante no pré-natal, como rastreamento sorológico e tratamento correto e oportuno da sífilis materna,

\begin{tabular}{|c|c|c|}
\hline Procedimento & Frequência e duração & 0 que avaliar \\
\hline \multicolumn{3}{|l|}{ Criança exposta à sífilis } \\
\hline \multirow{4}{*}{$\begin{array}{l}\text { Consultas ambulatoriais } \\
\text { de puericultura e exames } \\
\text { laboratoriais }\end{array}$} & $\begin{array}{l}\text { Seguimento ambulatorial na rotina da puericultura, } \\
\text { conforme recomendação da Saúde da Criança: na } 1^{\text {a }} \\
\text { semana de vida e nos meses } 1,2,4,6,9,12 \text { e } 18 \text {, com } \\
\text { retorno para checagem de exames complementares, } \\
\text { se for } 0 \text { caso. }\end{array}$ & $\begin{array}{l}\text { A criança exposta à sífilis, mesmo que não tenha sido diagnosticada } \\
\text { com sífilis congênita no momento no nascimento, pode apresentar } \\
\text { sinais e sintomas compatíveis com a doença ao longo do seu } \\
\text { desenvolvimento. Dessa forma, deve ser realizada busca ativa de } \\
\text { sinais e sintomas a cada retorno referente às manifestações precoces } \\
\text { de sífilis congênita e ao desenvolvimento neuropsicomotor. }\end{array}$ \\
\hline & \multirow{3}{*}{$\begin{array}{l}\text { Avaliação laboratorial com teste não treponêmico } \\
\text { (TNT) com 1, 3, 6, 12 e } 18 \text { meses de idade, } \\
\text { interrompendo o seguimento após dois testes não } \\
\text { reagentes consecutivos. }\end{array}$} & $\begin{array}{l}\text { Espera-se que os TNT declinem aos } 3 \text { meses de idade, devendo ser } \\
\text { não reagentes aos } 6 \text { meses caso a criança não tenha sido infectada e } \\
\text { seja apenas passagem passiva de anticorpo materno. }\end{array}$ \\
\hline & & $\begin{array}{l}\text { Se no seguimento ocorrer elevação de títulos em duas diluições em } \\
\text { TNT ou persistência da titulação aos } 6 \text { meses de idade, a criança } \\
\text { deverá ser investigada, submetida a coleta de líquor, tratada para } \\
\text { sífilis congênita com benzilpenicilina potássica (cristalina) por } 10 \\
\text { dias e notificada à vigilância epidemiológica. }\end{array}$ \\
\hline & & $\begin{array}{l}\text { A partir dos } 18 \text { meses de idade, se não houver achados clínicos e } \\
\text { laboratoriais, exclui-se sífilis congênita. }\end{array}$ \\
\hline \multicolumn{3}{|c|}{ Criança com sífilis congênita } \\
\hline $\begin{array}{l}\text { Consultas ambulatoriais } \\
\text { de puericultura e exames } \\
\text { laboratoriais }\end{array}$ & $\begin{array}{l}\text { Seguimento ambulatorial na rotina da puericultura, } \\
\text { conforme recomendação da Saúde da Criança: na } 1^{\text {a }} \\
\text { semana de vida e nos meses } 1,2,4,6,9,12 \text { e } 18 \text {, com } \\
\text { retorno para checagem de exames complementares, } \\
\text { se for } 0 \text { caso. }\end{array}$ & $\begin{array}{l}\text { Espera-se que os TNT declinem aos } 3 \text { meses de idade, devendo } \\
\text { ser não reagentes aos } 6 \text { meses caso a criança tenha sido } \\
\text { adequadamente tratada. }\end{array}$ \\
\hline \multirow{6}{*}{$\begin{array}{l}\text { Consultas com } \\
\text { especialistas }\end{array}$} & $\begin{array}{l}\text { Avaliação laboratorial com TNT com 1, 3, 6, } 12 \text { e } 18 \\
\text { meses de idade, interrompendo o seguimento após } \\
\text { dois testes não reagentes consecutivos. }\end{array}$ & $\begin{array}{l}\text { Diante da elevação de títulos em duas diluições em TNT ou sua não } \\
\text { negativação até } 18 \text { meses ou persistência de títulos baixos, reavaliar } \\
\text { a criança e proceder ao retratamento. }\end{array}$ \\
\hline & $\begin{array}{l}\text { Nas crianças com neurossífilis, repetir o exame de } \\
\text { líquor a cada seis meses, até a normalização citológica, } \\
\text { sorológica e bioquímica. }\end{array}$ & $\begin{array}{l}\text { Alterações liquóricas persistentes indicam necessidade de } \\
\text { reavaliação clínico-laboratorial completa e retratamento. }\end{array}$ \\
\hline & \multirow{4}{*}{$\begin{array}{l}\text { Consulta oftalmológica, audiológica e } \\
\text { neurológica semestrais por dois anos. }\end{array}$} & $\begin{array}{l}\text { Se a criança for tratada de forma não adequada, quanto à dose ou } \\
\text { tempo preconizado, realizar busca ativa da criança para reavaliação } \\
\text { clínico-laboratorial e reinício do tratamento. }\end{array}$ \\
\hline & & $\begin{array}{l}\text { Buscar anomalias oftalmológicas. As mais comuns são ceratite } \\
\text { intersticial, coriorretinite, glaucoma secundário, cicatriz córnea e } \\
\text { atrofia óptica. A faixa etária de acometimento de ceratite intersticial } \\
\text { costuma ser dos } 2 \text { aos } 20 \text { anos. }\end{array}$ \\
\hline & & $\begin{array}{l}\text { Buscar anomalias auditivas. A perda auditiva sensorial pode } \\
\text { ter ocorrência mais tardia, entre } 10 \text { e } 40 \text { anos de idade, por } \\
\text { acometimento do } 8^{\circ} \text { par craniano. }\end{array}$ \\
\hline & & Avaliar o desenvolvimento neuropsicomotor. \\
\hline
\end{tabular}

Fonte: adaptado do Protocolo Clínico e Diretrizes Terapêuticas para Atenção Integral às Pessoas com Infecções Sexualmente Transmissíveis, 2020. ${ }^{4}$

Figura 5 - Seguimento clínico-laboratorial das crianças expostas à sífilis e com sífilis congênita 
instituído o mais precocemente possível. A efetividade da assistência prestada à gestante precisa considerar todos esses parâmetros para evitar a transmissão vertical do T. pallidum.

Estimular a participação do pai ou parceiro durante todo o pré-natal é essencial para 0 bem-estar biopsicossocial da mãe, do bebê e dele próprio. É fundamental a implementação do pré-natal do homem e seu tratamento no caso de sífilis ou de outra IST. ${ }^{38,39}$ Destaca-se que, além do parceiro estável ou pai da criança, é possível que a gestante tenha outras parcerias sexuais. Assim, a equipe de saúde deve estar atenta e assistir todas as pessoas com quem a gestante se relaciona sexualmente.

A sífilis adquirida, a sífilis em gestantes e a sífilis congênita são doenças de notificação compulsória e devem ser notificadas em fichas próprias, encaminhadas à vigilância epidemiológica. ${ }^{4}$ Importante destacar que, a despeito da melhoria observada, ainda é bastante incipiente a notificação de casos de sífilis em gestantes e em suas parcerias sexuais, e de sífilis congênita em unidades de saúde pública e suplementar, o que contribui para a subestimação da ocorrência da sífilis no país. A priorização de políticas públicas com envolvimento de autoridades sanitárias, gestores de saúde e população geral pode levar a mudanças no cenário atual da sífilis no país.

\section{Contribuição dos autores}

Domingues CSB, Duarte G, Passos MRL, Sztajnbok DCN e Menezes MLB redigiram o manuscrito, aprovaram a versão final e são responsáveis por todos os seus aspectos, incluindo a garantia de sua precisão e integridade.

\section{Agradecimento}

Os autores agradecem a contribuição para a realização deste trabalho aos membros do grupo técnico de especialistas responsáveis pela elaboração do PCDT para Atenção Integral às Pessoas com IST 2020.

\section{Referências}

1. Brasil. Ministério da Saúde. Portaria MS/SCTIE $n^{0} 42$, de 5 de outubro de 2018. Torna pública a decisão de aprovar o Protocolo Clínico e Diretrizes Terapêuticas para Atenção Integral às Pessoas com Infecções Sexualmente Transmissíveis (IST), no âmbito do Sistema Único de Saúde - SUS [Internet]. Diário Oficial da União, Brasília (DF), 2018 out 8 [citado 2020 jul 31]; Seção 1:88. Disponível em: http://bvsms.saude.gov.br/ bvs/saudelegis/sctie/2018/prt0042_08_10_2018.html

2. Korenromp EL, Rowley J, Alonso M, Mello MB, Wijesooriya NS, Mahiané SG, et al. Global burden of maternal and congenital syphilis and associated adverse birth outcomes - Estimates for 2016 and progress since 2012. PLoS One [internet]. 2019 Feb [cited $2020 \mathrm{Jul} 1$ 1]; 14(2):e0211720. Available from: https://doi.org/10.1371/journal.pone.0211720

3. Ministério da Saúde (BR). Secretaria de Vigilância em Saúde. Departamento de Doenças de Condições Crônicas e Infecções Sexualmente Transmissíveis. Sífilis | 2019. Bol Epidemiol [Internet]. 2019 out [citado 2020 out 15]; especial. Disponível em: http://www.aids.gov. br/pt-br/pub/2019/boletim-epidemiologico-sifilis-2019

4. Ministério da Saúde (BR). Secretaria de Vigilância em Saúde. Departamento de Doenças de Condições

Crônicas e Infecções Sexualmente Transmissíveis. Protocolo clínico e diretrizes terapêuticas para atenção integral às pessoas com infecções sexualmente transmissíveis (IST) [Internet]. Brasília: Ministério da Saúde; 2020 [citado 2020 out 15]. Disponível em: http://www.aids.gov.br/pt-br/ pub/2015/protocolo-clinico-e-diretrizes-terapeuticas-para-atencao-integral-pessoas-com-infeccoes

5. Reyes MP, Hunt N, Ostrea Jr EM, George D. Maternal/congenital syphilis in a large tertiary-care urban hospital. Clin Infect Dis [Internet]. 1993 Dec [cited 2020 0ct 15]; 17(6):1041-6. Available from: https://doi.org/10.1093/clinids/17.6.1041

6. Caddy SC, Lee BE, Sutherland K, Robinson JL, Plitt SS, Read R, et al. Pregnancy and neonatal outcomes of women with reactive syphilis serology in Alberta, 2002 to 2006. J Obstet Gynaecol Can [Internet]. 2011 May [cited 2020 0ct 15]; 33(5):453-9. Available from: https://doi.org/10.1016/s1701-2163(16)34878-2

7. Lago EG, Vaccari A, Fiori RM. Clinical features and follow-up of congenital syphilis. Sex Transm Dis [Internet]. 2013 Feb [cited 2020 Oct 15]; 40(2):85-94. Available from: https:// doi.org/10.1097/olq.0b013e31827bd688 
8. Grimpel E, Sanchez PJ, Wendel GD, Burstain JM, McCracken Jr GH, Radolf JD, et al. Use of polymerase chain reaction and rabbit infectivity testing to detect Treponema pallidum in amniotic fluid, fetal and neonatal sera, and cerebrospinal fluid. J Clin Microbiol [Internet]. 1991 Aug [cited 2020 0ct 15]; 29(8):1711-18. Available from: https://doi.org/10.1128/jcm.29.8.1711-1718.1991

9. Nathan L, Twickler DM, Peters MT, Sánchez PJ, Wendel Jr GD. Fetal syphilis: correlation of sonographic findings and rabbit infectivity testing of amniotic fluid. J Ultrasound Med [Internet]. 1993 Feb [cited 2020 0ct 15]; 12(2):97-101. Available from: https://doi.org/10.7863/jum.1993.12.2.97

10. Qureshi F, Jacques SM, Reyes MP. Placental histopathology in syphilis. Hum Pathol [Internet]. 1993 Jul [cited 2020 0ct 15]; 24(7):779-84. Available from: https://doi.org/10.1016/0046-8177(93)90016-a

11. Workowski KA, Bolan GA, Centers for Disease Control and Prevention. Sexually transmitted diseases treatment guidelines, 2015. MMWR Recomm Rep [Internet]. 2015 Jun [cited 2020 Jun 25]; 64(RR03):1-137. Available from: https://www.cdc.gov/ mmwr/preview/mmwrhtml/rr6403a1.htm

12. Berman SM. Maternal syphilis: pathophysiology and treatment. Bull World Health Organization [Internet]. 2004 [cited 2020 Jun 25]; 82(6):433-8. Available from: https://www. who.int/bulletin/volumes/82/6/433.pdf?ua=1

13. Hawkes SJ, Gomez GB, Broutet N. Early antenatal care: does it make a difference to outcomes of pregnancy associated with syphilis? A systematic review and meta-analysis. PLoS One [internet]. 2013 Feb [cited 2020 Jun 25]; 8(2):e56713. Available from: https://doi.org/10.1371/journal.pone.0056713

14. Centers for Disease Control and Prevention (CDC). Congenital syphilis - United States, 1998. MMWR Morb Mortal Wkly Rep [Internet]. 1999 Sep [cited 2020 Jun 25]; 48(34):757-61. Available from: https://www.cdc. gov/mmwr/preview/mmwrhtml/mm4834a3.htm

15. Blencowe H, Cousens S, Kamb M, Stuart Berman S, Lawn JE. Lives saved tool supplement detection and treatment of syphilis in pregnancy to reduce syphilis related stillbirths and neonatal mortality. BMC Public Health [Internet]. 2011 Apr [cited 2020 0ct 15]; 11(Suppl 3):S9. Available from: https://doi.org/10.1186/1471-2458-11-s3-s9

16. Ortiz-Lopez N, Diez M, Diaz 0, Simon F, Diaz A. Epidemiological surveillance of congenital syphilis in Spain, 2000-2010. Pediatr Infect Dis J [Internet]. 2012 Sep [cited 2020 0ct 15]; 31(9):988-90. Available from: https://doi.org/10.1097/inf.0b013e31825d3152

17. Bowen V, Su J, Torrone E, Kidd S, Weinstock H. Increase in incidence of congenital syphilis, United States, 2012-2014. MMWR Morb Mortal Wkly Rep [Internet]. 2015 Nov [cited 2020 Jul 5]; 64(44):1241-45. Available from: https://www.cdc.gov/mmwr/pdf/wk/mm6444.pdf

18. Herremans T, Kortbeek L, Notermans DW. A review of diagnostic tests for congenital syphilis in newborns. Eur J Clin Microbiol Infect Dis [Internet]. 2010 May [cited 2020 0ct 15]; 29(5):495-501. Available from: https://doi.org/10.1007/s10096-010-0900-8

19. Woods CR. Syphilis in children: congenital and acquired. Semin Pediatr Infect Dis [Internet]. 2005 Oct [cited 2020 0ct 15]; 16(4):245-57. Available from: https://doi.org/10.1053/j.spid.2005.06.005

20. Rawstron SA, Hawkes SJ. Treponema pallidum (syphilis). In: Long SS, Pickering LK, Prober CG, editors. Principles and practice of pediatric infectious diseases. 4th ed. Edinburgh; New York: Elsevier Churchill Livingstone; 2012. p. 941.

21. Kwak J, Lamprecht C. A review of the guidelines for the evaluation and treatment of congenital syphilis. Pediatr Ann [Internet]. 2015 May [cited 2020 0ct 15]; 44(5):e108-14. Available from: https://doi.org/10.3928/00904481-20150512-10

22. Wicher V, Wicher K. Pathogenesis of maternal-fetal syphilis revisited. Clin Infect Dis [Internet]. 2001 Aug [cited 2020 0ct 15]; 33(3):354-63. Available from: https://doi.org/10.1086/321904

23. Baker CJ, editor. Red book: atlas of pediatric infectious diseases. 4th ed. Itasca: American Academy of Pediatrics; 2020.

24. Ministério da Saúde (BR). Secretaria de Vigilância em Saúde. Departamento de Vigilância, Prevenção e Controle das Infecções Sexualmente Transmissíveis, do HIV/Aids e das Hepatites Virais. Protocolo clínico e diretrizes terapêuticas para prevenção da transmissão vertical de HIV, sífilis e hepatites virais [Internet]. Brasília: Ministério da Saúde; 2015 [citado 2020 out 15]. Disponível em: http://www.aids.gov.br/pt-br/ pub/2015/protocolo-clinico-e-diretrizes-terapeuticas-para-prevencao-da-transmissao-vertical-de-hiv

25. Woods CR. Congenital syphilis-persisting pestilence. Pediatr Infect Dis J [Internet]. 2009 Jun [cited 2020 0ct 15]; 28(6):536-37. Available from: https://doi.org/10.1097/inf.0b013e3181ac8a69 
26. Rawstron SA, Mehta S, Marcellino L, Rempel J, Chery F, Bromberg K. Congenital syphilis and fluorescent treponemal antibody test reactivity after the age of 1 year. Sex Transm Dis [Internet]. 2001 Jul [cited 2020 0ct 15]; 28(7):412-6. Available from: https:// doi.org/10.1097/00007435-200107000-00009

27. Morshed MG, Singh AE. Recent trends in the serologic diagnosis of syphilis. Clin Vaccine Immunol [Internet]. 2015 Feb [cited 2020 0ct 25]; 22(2):137-47. Available from: https://doi.org/10.1128/cvi.00681-14

28. World Health Organization - WHO. Laboratory diagnosis of sexually transmitted infections, including human immunodeficiency virus. Geneva: WH0; 2013 [cited 2020 Jul 16]. 228 p. Available from: https:/apps.who.int/iris/bitstream/handle/10665/85343/9789241505840_eng.pdf?sequence $=1$

29. Brasil. Ministério da Saúde. Portaria MS/GM n ${ }^{\circ}$ 3.161, de 27 de dezembro de 2011. Dispõe sobre a administração da penicilina nas unidades de Atenção Básica à Saúde, no âmbito do Sistema Único de Saúde (SUS) [Internet]. Diário Oficial da União, Brasília (DF), 2011 dez 28 [citado 2020 jul 3]; Seção 1:54. Disponível em: http://bvsms.saude.gov.br/bvs/ saudelegis/gm/2011/prt3161_27_12_2011.html

30. Conselho Federal de Enfermagem - COFEN (BR). Nota técnica Cofen/CTLN n ${ }^{\circ}$ 03, de 14 de junho de 2017, que reforça a importância da administração de penicilina benzatina nas unidades básicas de saúde para conter avanço da sífilis. Brasília: COFEN; 2017 [citado 2020 jul 3]. Disponível em: http://www. cofen.gov.br/wp-content/uploads/2017/06/NOTA-T\%C3\%89CNICA-COFEN-CTLN-N\%C2\%B0-03-2017.pdf

31. Ministério da Saúde (BR). Secretaria de Atenção à Saúde. Departamento de Atenção Básica. Acolhimento à demanda espontânea: queixas mais comuns na Atenção Básica [Internet]. Brasília: Ministério da Saúde; 2013 [citado 2020 out 15]. (Cadernos de Atenção Básica, n. 28, v. II.). Disponível em: https:// aps.saude.gov.br/biblioteca/visualizar/MTIwNA

32. Galvao TF, Silva MT, Serruya SJ, Newman LM, Klausner JD, Pereira MG, et al. Safety of benzathine penicillin for preventing congenital syphilis: a systematic review. PLoS One [Internet]. $2013 \mathrm{Feb}$ [cited 2020 Jul 4]; 8(2):e56463. Available from: https://doi.org/10.1371/journal.pone.0056463

33. Ministério da Saúde (BR). Secretaria de Vigilância em Saúde. Departamento de Vigilância, Prevenção e Controle das Infecções Sexualmente Transmissíveis, do HIV/Aids e das Hepatites Virais. Nota Informativa $\mathrm{n}^{0} 2$-SEI/2017-.DIAHV/SVS/MS. Altera os critérios de definições de casos para notificação de sífilis adquirida, sífilis em gestantes e sífilis congênita. SEI/ MS No 0882971 [Internet]. Brasília: Ministério da Saúde; 2017 [citado 2020 jul 31]. Disponível em: http://portalsinan.saude.gov.br/images/documentos/ Agravos/Sifilis-Ges/Nota_Informativa_Sifilis.pdf

34. Seña AC, Wolff M, Behets F, Martin DH, Leone P, Langley C, et al. Rate of decline in nontreponemal antibody titers and seroreversion after treatment of early syphilis. Sex Transm Dis [Internet]. 2017 Jan [cited 2020 0ct 15]; 44(1):6-10. Available from: https:// www.ncbi.nlm.nih.gov/pmc/articles/PMC5270385/

35. Brown ST, Zaidi A, Larsen SA, Reynolds GH. Serological response to syphilis treatment. A new analysis of old data. JAMA [Internet]. 1985 Mar [cited 2020 0ct 15]; 253(9):1296-9. Available from: https://jamanetwork. com/journals/jama/article-abstract/397156

36. Ministério da Saúde (BR). Secretaria de Atenção à Saúde. Departamento de Atenção Básica. Saúde da criança: crescimento e desenvolvimento [Internet]. Brasília: Ministério da Saúde; 2012 [citado 2020 out 15]. (Cadernos de Atenção Básica, n. 33). Disponível em: http://bvsms.saude.gov.br/bvs/publicacoes/ saude_crianca_crescimento_desenvolvimento.pdf

37. Ministério da Saúde (BR). Secretaria de Vigilância em Saúde. Departamento de Análise de Situação de Saúde. Sistema de Informação sobre Nascidos Vivos - SINASC. DATASUS-Tabnet [internet]. Brasília: Ministério da Saúde; 2018 [citado 2020 jul 7]. Disponível em: http://tabnet.datasus. gov.br/cgi/tabcgi.exe?sinasc/cnv/nvsp.def

38. Duarte G. Extensão da assistência pré-natal ao parceiro como estratégia de aumento da adesão ao pré-natal e redução da transmissão vertical de infecções. Rev Bras Ginecol Obstet [internet]. 2007 [citado 2020 jul 5]; 29(4):171-4. Disponível em: https://www.scielo.br/pdf/rbgo/v29n4/a01v29n4.pdf

39. Ministério da Saúde (BR). Secretaria de Atenção à Saúde. Departamento de Ações Programáticas Estratégicas. Coordenação Nacional de Saúde do Homem. Guia do pré-natal do parceiro para profissionais de saúde [Internet]. Brasília: Ministério da Saúde; 2016 [citado 2020 out 15]. 55 p. Disponível em: https://portalarquivos2.saude.gov.br/ images/pdf/2016/agosto/11/guia_PreNatal.pdf 


\section{Abstract}

The topics of congenital syphilis and children exposed to syphilis are part of the Clinical Protocol and Therapeutic Guidelines for Comprehensive Care for People with Sexually Transmitted Infections, published by the Brazilian Ministry of Health in 2020. The Protocol and Guidelines have been developed based on scientific evidence and validated in discussions with specialists. This article provides guidelines for clinical management of both syphilis in pregnant women and also congenital syphilis, emphasizing prevention of vertical transmission of Treponema pallidum. Epidemiological and clinical aspects of these infections are presented, as well as recommendations for health service managers regarding the programmatic and operational management of syphilis. The article also includes guidelines for bealth professionals on screening, diagnosing and treating people with sexually transmitted infections and their sex partners, in addition to strategies for syphilis surveillance, prevention and control actions.

Keywords: Syphilis; Congenital Syphilis; Prenatal Care; Diagnosis; Therapeutics; Monitoring.

\section{Resumen}

Los temas sífilis congénita y niños expuestos a la sífilis componen el Protocolo Clínico y Directrices Terapéuticas para la Atención Integral a Personas con Infecciones de Transmisión Sexual, publicado por el Ministerio de Salud de Brasil en 2020. Tal documento fue elaborado con base en evidencia científica y validado en discusiones con especialistas. Este artículo presenta directrices para el manejo clínico de la sífilis en mujeres embarazadas $y$ de la sífilis congénita, con énfasis en la prevención de la transmisión vertical del Treponema pallidum. Se contemplan aspectos epidemiológicos y clínicos de la infección, asi como recomendaciones para gerentes en la gestión programática y operativa de la sífilis. También se incluyen directrices para profesionales de la salud en la detección, diagnóstico y tratamiento de personas con infecciones de transmisión sexual y sus parejas sexuales, además de estrategias para acciones de vigilancia, prevención y control de la enfermedad.

Palabras clave: Sífilis; Sífilis Congénita; Atención Prenatal; Diagnóstico; Terapéutica; Monitoreo.

Recebido em 23/07/2020

Aprovado em 03/10/2020 


\section{Errata}

No artigo "Protocolo Brasileiro para Infecções Sexualmente Transmissíveis 2020: sífilis congênita e criança exposta à sífilis", doi: 10.1590/\$1679-4974202100005.esp1, Figura 1 - Testes imunológicos utilizados para o diagnóstico de sífilis, publicado no periódico Epidemiologia e Serviços de Saúde, v. 30(Esp.1):1-13, na página 4:

Onde se lia:

\begin{tabular}{|c|c|c|}
\hline $\begin{array}{l}\text { Testes } \\
\text { imunológicos }\end{array}$ & Tipos & Observações \\
\hline \multirow{4}{*}{ Não treponêmicos } & Venereal disease research laboratory (VDRL) & Quantificáveis (ex.: 1:2, 1:4, 1:8). \\
\hline & Rapid plasma reagin (RPR) & \multirow{3}{*}{$\begin{array}{l}\text { Importantes para o diagnóstico e monitoramento da resposta } \\
\text { ao tratamento. }\end{array}$} \\
\hline & Toluidine red unheated serum test (TRUST) & \\
\hline & Unheated-serum reagin (USR) & \\
\hline \multirow{7}{*}{ Treponêmicos } & Testes rápidos & São os primeiros a se tornarem reagentes. \\
\hline & $\begin{array}{l}\text { Teste de imunofluorescência indireta - Fluorescent treponemal } \\
\text { antibody-absorption (FTA-Abs) }\end{array}$ & $\begin{array}{l}\text { Na maioria das vezes, permanecem reagentes por toda a vida, } \\
\text { mesmo após o tratamento. }\end{array}$ \\
\hline & $\begin{array}{l}\text { Ensaios imunoenzimáticos - Enzyme-linked immunossorbent } \\
\text { assay (ELISA) }\end{array}$ & \multirow{5}{*}{$\begin{array}{l}\text { São importantes para o diagnóstico, mas não estão indicados } \\
\text { para monitoramento da resposta ao tratamento. }\end{array}$} \\
\hline & $\begin{array}{l}\text { Ensaio imunológico com revelação quimioluminescente e suas } \\
\text { derivações - Electrochemiluminescence (EQL) e Chemiluminescent } \\
\text { magnetic immunoassay (CMIA) }\end{array}$ & \\
\hline & $\begin{array}{l}\text { Teste de hemaglutinação - T. pallidum haemagglutination test } \\
\text { (TPHA) }\end{array}$ & \\
\hline & $\begin{array}{l}\text { Teste de aglutinação de partículas - T. pallidum particle } \\
\text { agglutination assay (TPPA) }\end{array}$ & \\
\hline & $\begin{array}{l}\text { Ensaios de micro-hemaglutinação - Micro-haemagglutination } \\
\text { assay (MHA-TP) }\end{array}$ & \\
\hline
\end{tabular}

Leia-se:

\begin{tabular}{|l|l|l|}
\hline $\begin{array}{l}\text { Testes } \\
\text { imunológicos }\end{array}$ & Tipos & Observações \\
\hline \multirow{4}{*}{ Não treponêmicos } & Venereal disease research laboratory (VDRL) & Quantificáveis (ex.: 1:2, 1:4, 1:8). \\
\cline { 2 - 2 } & Rapid plasma reagin (RPR) & $\begin{array}{l}\text { Importantes para o diagnóstico e monitoramento da resposta } \\
\text { ao tratamento. }\end{array}$ \\
\cline { 2 - 2 } & Toluidine red unheated serum test (TRUST) & \\
\cline { 2 - 2 } & Unheated-serum reagin (USR) & \\
\hline
\end{tabular}


Continuação

\begin{tabular}{|c|c|c|}
\hline $\begin{array}{l}\text { Testes } \\
\text { imunológicos }\end{array}$ & Tipos & Observações \\
\hline \multirow{7}{*}{ Treponêmicos } & Testes rápidos & \multirow{7}{*}{$\begin{array}{l}\text { São os primeiros a se tornarem reagentes. } \\
\text { Na maioria das vezes, permanecem reagentes por toda a vida, } \\
\text { mesmo após o tratamento. } \\
\text { São importantes para o diagnóstico, mas não estão indicados } \\
\text { para monitoramento da resposta ao tratamento. }\end{array}$} \\
\hline & $\begin{array}{l}\text { Teste de imunofluorescência indireta - Fluorescent treponemal } \\
\text { antibody-absorption (FTA-Abs) }\end{array}$ & \\
\hline & $\begin{array}{l}\text { Ensaios imunoenzimáticos - Enzyme-linked immunossorbent } \\
\text { assay (ELISA) }\end{array}$ & \\
\hline & $\begin{array}{l}\text { Ensaio imunológico com revelação quimioluminescente e suas } \\
\text { derivações - Electrochemiluminescence (EQL) e Chemiluminescent } \\
\text { magnetic immunoassay (CMIA) }\end{array}$ & \\
\hline & $\begin{array}{l}\text { Teste de hemaglutinação - T. pallidum haemagglutination test } \\
\text { (TPHA) }\end{array}$ & \\
\hline & $\begin{array}{l}\text { Teste de aglutinação de partículas - T. pallidum particle } \\
\text { agglutination assay (TPPA) }\end{array}$ & \\
\hline & $\begin{array}{l}\text { Ensaios de micro-hemaglutinação - Micro-haemagglutination } \\
\text { assay (MHA-TP) }\end{array}$ & \\
\hline
\end{tabular}

